\title{
A REVIEW OF CODE PROVISIONS FOR TORSIONAL SEISMIC EFFECTS IN BUILDINGS
}

\author{
T Paulay ${ }^{1}$
}

\begin{abstract}
SUMMARY
A series of recent studies of the seismic torsional response of ductile buildings is condensed and extended to serve as a basis for recommendations for possible amendments of the relevant clauses of the current New Zealand loadings standard [1]. It is postulated that the primary seismic design aim, associated with criteria of the ultimate limit state, should address displacement ductility demands and supply, as affected by twisting of the system, rather than torsional strength. Some well-established parameters, such as yield displacement, element and system stiffness, are redefined to enable the inelastic deformation pattern of rigid diaphragms to be simply quantified. The presentation concludes with specific recommendations and corresponding commentaries in a form suitable, with editorial modifications, for possible adoption as codified design requirements. To illustrate both the relevance of the recommendations and their simplicity, two numerical examples, showing the evaluation of the displacement ductility capacity of a model structure, are appended.
\end{abstract}

\section{INTRODUCTION}

Although design procedures for the seismic response of building structures, as affected by torsional effects, have been embodied in most national building codes [2], continued extensive publications demonstrate that the research community is not satisfied with current approaches and that it is preoccupied with finding improved solutions [3-10].

Current code provisions, used world wide, are based on well established principles of elastic structural behaviour. While very significant progress has been made in the seismic design of structures to be designed to rely on inelastic deformation capacity, no corresponding guidance with respect to torsional aspects of ductile response is apparent in current code recommendations.

Several of the recent theoretical studies, which critically examined the appropriateness of established code rules, attempted to modify existing eccentricity parameters to achieve a better agreement with the findings extracted from the dynamic analyses of non-linear structural models. Because existing procedures are based on well understood principles of elastic structural behaviour, the justification of eccentricity modifications in recognition of nonlinear response is not transparent to the code user. The lack of both rationale and recognition of the features of ductile behaviour, is likely to perturb the confidence of the discriminating design practitioner. Therefore, it is subsequently recommended in this review that distinctly different approaches to the treatment of torsional phenomena of elastic and ductile structural response be adopted.
While the principles have general validity, the proposed design strategy is illustrated mainly with references to reinforced concrete structures.

\section{AIMS OF THE DESIGN STRATEGY}

\subsection{Serviceability Limit State}

Criteria to meet the serviceability limit state for seismic design are clearly defined [1]. With regard to torsional phenomena, attention must be primarily given to displacements induced in elements, affecting also the building content in general, for which translation-and torsion-induced actions are additive. Because the structural system is expected to respond well within the elastic domain, the relevant and well established principles of structural mechanics are applicable. These principles are expected to be familiar and hence are not reviewed here.

Another consideration is the allocation of strength to all elements to ensure that, as a consequence of the application of appropriate design forces, which are generally smaller than those associated with ultimate limit state, no inelastic structural deformations will occur. Corresponding recommendations are summarized in Section 4.1.

\section{$2.2 \quad$ Ultimate Limit State}

For systems the seismic design of which relies on ductile response, the design criteria should be as follows:

- $\quad$ Earthquake-induced deformations, including system twist, should be such as to limit the expected 
displacement ductility demand on any element to its ductility capacity, $\mu_{\Delta i, \max }$.

-

Magnitudes of interstorey displacements, to be expected at locations remote from the centre of twist, should not exceed those considered acceptable [1]

The purpose of considering torsional effects in ductile system should be, therefore, to account for twist-imposed inelastic displacements on certain elements, rather than to provide torsional resistance. The word "twist" is used deliberately in this context to emphasize, in contrast to existing code provisions [1, 2], the need to address torsion- induced displacement demands. Corresponding recommendations for code provisions are presented in Section 4.3 .

\section{FEATURES OF THE TORSIONAL RESPONSE DUCTILE SYSTEMS}

In a number of recent publications [11 to 14$]$ the translational and twist-induced displacements imposed on both elastic and inelastic elements of ductile structural system was studied. In particular attempts were made to establish simple relationships between expected, earthquake-imposed displacement ductility demands on the system and those on its critical elements. Because the recommendation for new code provisions presented in Section 4.3 are based on these recent studies, the highlight of the conclusions are briefly summarized in this section.

\subsection{A Review of Definitions}

\subsubsection{Element displacement ductility}

Displacement ductility has been traditionally defined in New Zealand as the ratio of the ultimate displacement to the yield displacement, i.e., $\mu_{\Delta}=\Delta_{\mathrm{u}} / \Delta_{\mathrm{y}}$. For a structural system, such as shown in figure 1, these displacements refer to the centre of mass, $\mathrm{CM}$, where the earthquake-induced inertia force is assumed to be generated. The system ductility demands, subsequently denoted as $\mu_{\Delta}$, is the most critical parameter [1] controlling the magnitude of the ultimate limit state design base shear force.

The displacement ductility relevant to an element, i, within a system is similarly defined as $\mu_{\Delta \mathrm{i}}=\Delta_{\mathrm{ui}} / \Delta_{\mathrm{yi}}$. The element yield displacement, for example that of a reinforced concrete cantilever wall, is traditionally defined as that induced by the lateral design force, $\mathrm{V}_{\mathrm{i}}$, in the elastic prismatic element. With respect to the roof level, this is in the form of

$$
\Delta_{\mathrm{yi}}=\gamma_{1} \frac{\mathrm{V}_{\mathrm{i}} \mathrm{h}_{\mathrm{w}, \mathrm{i}}^{3}}{\mathrm{EI}_{\mathrm{i}}}
$$

where $h_{w, i}:$ height of element

$\mathrm{EI}_{\mathrm{i}} \quad$ : effective flexural rigidity of the wall section taking into account the extent of cracking a constant associated with the assumed pattern of distributed lateral design forces. As an example, for an inverted triangular pattern, $\gamma_{1}=11 / 60$

Accordingly, as equation (1) shows, the displacements, $\Delta_{\max }$ of elements with identical heights and force patterns are affected by both base shear, $\mathrm{V}_{\mathrm{i}}$, and flexural rigidity, $\mathrm{EI}_{\mathrm{i}}$.

The yield displacement is, however, primarily affected by the yield curvature, $\phi_{y i}$, at the base of the element. It depends solely on the yield strains at one or both boundaries of the section and the length, $\ell_{\omega}$, of the element. The yield curvature may be expressed as

$$
\phi_{\mathrm{yi}}=\frac{\lambda \varepsilon_{\mathrm{y}}}{\ell_{\mathrm{wi}}}
$$

where $\lambda$ is a constant which defines the ratio of the nominal flexural strength, $M_{n}$, to that of the moment, $M_{y}$, at the onset of the yield strain, $\varepsilon_{y}$, at the extreme tension fibre, and the relative neutral axis depth of the sections [15]. For reinforced concrete structural walls typically $\lambda \cong 1.6$. For a symmetrical steel section subjected to flexure only $\lambda=2.0$.

It should be noted that the yield curvature, $\phi_{y}$, given by equation (2) and hence the yield displacement, $\Delta_{y}$, is primarily a property dependent on the geometry of the section and level of axial load. It is largely independent of strength and of the flexural rigidity, $\mathrm{EI}_{\mathrm{i}}$

By replacing the classical term $\phi=M / E I$ by equation (2) in those cases when the yield curvature, $\phi_{\mathrm{yi}}$, is relevant to element deformation [15], equation (1) is simply modified to give the yield displacement of a cantilever wall, say at roof level, in this form

$$
\Delta_{\mathrm{yi}}=\frac{\gamma_{1} \lambda \varepsilon_{\mathrm{y}} \mathrm{A}_{\mathrm{ri}} \mathrm{h}_{\mathrm{wi}}}{\gamma_{2}}
$$

where

$$
\begin{aligned}
: & \text { the constants } \gamma_{1} \text { and } \lambda \text { were defined for } \\
& \text { equations (1) and (2) } \\
\gamma_{2}: & \begin{array}{l}
\text { the fraction of the height, } \mathrm{h}_{\text {wi }} \text {, at which the } \\
\text { resultant of the lateral forces acts. For an } \\
\text { inverted triangular force pattern, } \\
\text { previously used, } \gamma_{2}={ }^{2} / 3
\end{array} \\
\mathrm{~A}_{\mathrm{ri}}: & \text { the aspect ratio, } \mathrm{h}_{\mathrm{wi}} / \ell_{\mathrm{wi}} \text { of the wall }
\end{aligned}
$$

In the case of reinforced concrete elements, such as similarly reinforced cantilever walls with identical heights, $h_{w}$, equation (3) simplifies to

$$
\Delta_{\mathrm{yi}}=\left[\frac{\gamma_{1} \lambda \varepsilon_{\mathrm{y}}}{\gamma_{2}} \mathrm{~h}_{\mathrm{w}}^{2}\right] / \ell_{\mathrm{wi}}=\xi / \ell_{\mathrm{wi}}
$$

where the bracketed term, $\xi$, is a constant. This then leads to the important conclusion that the yield displacement, $\Delta_{\mathrm{yi}}$, is inversely proportional to the element length, $\ell_{w i}$ and, as stated earlier, it is independent of element strength and flexural 
rigidity. It is therefore evident that elements with different lengths, cannot yield simultaneously.

In routine design, usually relative values may be used and thus it may be assumed that $\Delta_{\mathrm{yi}} \propto 1 / \ell_{\text {wi }}$

With the definition by equation (4) of the relative element yield displacement, the element displacement ductility factor, $\mu_{\Delta \mathrm{i}}=\Delta_{\mathrm{ui}} / \Delta_{\mathrm{yi}}$ is quantified.

\subsubsection{System displacement ductility}

A simple definition of the system yield displacement, $\Delta_{y}$, may be formulated with the aid of an example structure, to be used subsequently. Its plan is shown in figure 1(a). The design earthquake base shear force acting through the centre of mass, $\mathrm{CM}$, in the $\mathrm{y}$ direction is defined as $\mathrm{V}_{\mathrm{Ey}}$. When the associated inelastic system translation in the y direction is considered, the evaluation of the yield displacement, of all elements, such as (1) to (4) using equation (4), is necessary. Because the lengths of these elements are different, i.e., in this example $\ell_{w 2}=$ $\ell_{\mathrm{w} 4}=0.7 \ell_{\mathrm{w} 1}$ and $\ell_{\mathrm{w} 3}=0.5 \ell_{\mathrm{wl}}$, the element yield displacements, $\Delta_{y i}$, as defined by equation (4) and shown in figure 1 (b), are also different. The strengths assigned in the design to these elements, to be examined subsequently, are such that

$$
\mathrm{V}_{1}=0.448 \mathrm{~V}_{\mathrm{Ey}}, \mathrm{V}_{2}=\mathrm{V}_{4}=0.220 \mathrm{~V}_{\mathrm{Ey}} \text { and } \mathrm{V}_{3}=0.112 \mathrm{~V}_{\mathrm{Ey}} \text {. }
$$

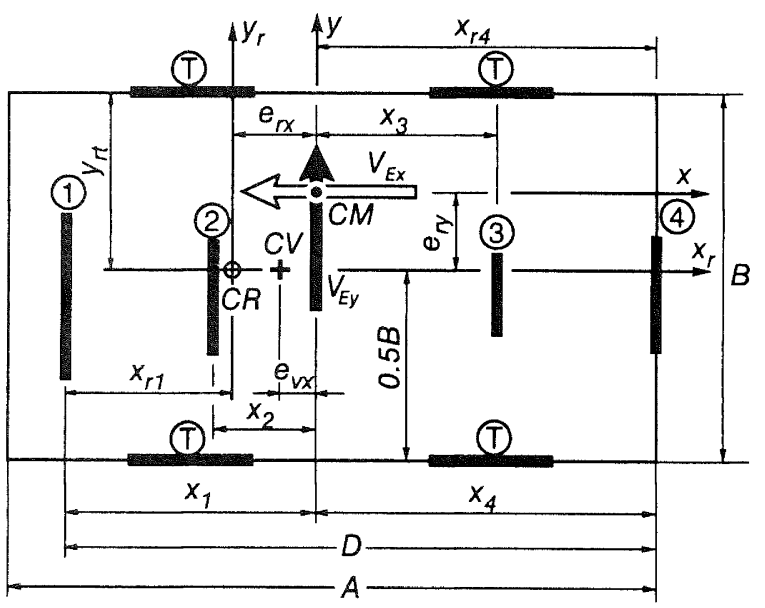

(a) Plan

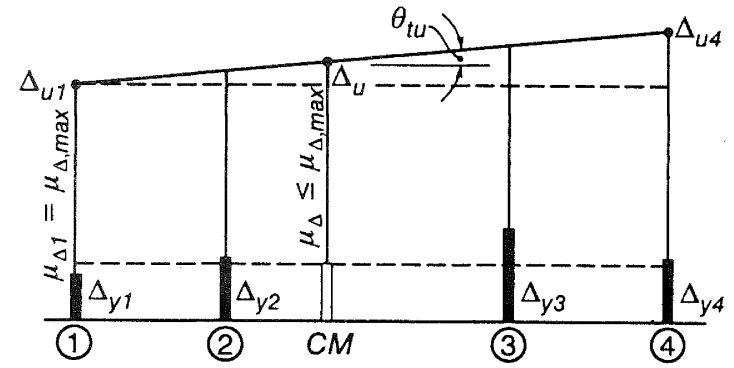

FIGURE 1. A torsionally restrained system subjected to ductility demand
The idealized bilinear force-displacement relationship for each these elements, controlled by uniform diaphragm translation, is shown in figure 2. Element strengths are expressed in terms of the base shear force, $V_{E y}$, and displacements shown are normalized in terms of the yield displacement of element (1). By approximating the nonlinear base shear-displacement relationship it is seen that the reference yield displacement of the system, $\Delta_{y}$, may be defined as

$$
\Delta_{y}=\frac{V_{\text {Ey }}}{\Sigma\left(V_{i} / \Delta_{y i}\right)}
$$

With appropriate values substituted for the example elements it is found that $\Delta_{y}=1.23$.

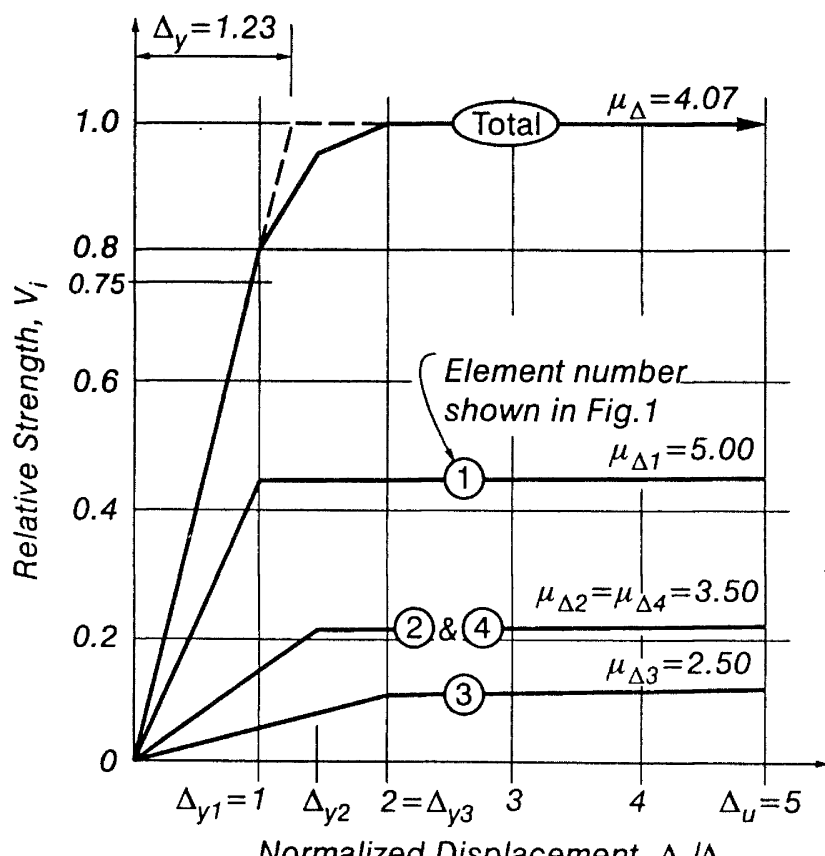

\section{FIGURE 2. Force-displacement relationships associated with uniform storey translation \\ [14]}

The element displacement ductility capacity, $\mu_{\Delta i \text { max }}$, should be in accordance with the specifications of the relevant material code. For reinforced concrete structural walls for example, $\mu_{\Delta, \max }=5[16,17]$. Thus the maximum uniform translation of the system shown in figure 1(a) is governed by the ultimate displacement capacity of the element with the smallest yield displacement, i.e., element (1), $\Delta_{\mathrm{ul}}=5 \Delta_{\mathrm{y} 1}=\Delta_{\mathrm{u}}$.

Based on the bilinear system response, the system displacement ductility factor may thus be defined as

$$
\mu_{\Delta}=\Delta_{u} / \Delta_{y}
$$

This then necessitates the limitation of the system displacement ductility demand to $\mu_{\Delta}=5.0 / 1.23=4.07$. It is also seen in figure 2 that the ductility demand on all other elements, with a capacity of $\mu_{\Delta \text {, max }}=5$, is not critical. 


\subsubsection{Element and system stiffness}

A definition of the yield displacement by equation (4), in contrast with that traditionally used (equation (1)), warrants also a redefinition of element stiffness. This is more appropriate to use in the design for the ultimate limit state. As figure 2 shows the bilinear idealisation of ductile element response suggests that the element stiffness be defined as

$$
k_{i}=\frac{V_{i}}{\Delta_{y i}}
$$

It is important to note that the yield displacement, of elements defined by equations (3) and (4), is essentially constant for elements with identical lengths, $\ell_{\text {wi }}$. This means that stiffness is strength dependent. In contrast the traditional approach employed in the design of reinforced concrete elements [15, 16] uses stiffness values based on the dimensions of the cross sections, ignoring the contribution to response of reinforcement, i.e., strength.

With this substitution, the definition of the system yield displacement (equation (5)) simplifies to

$$
\Delta_{\mathrm{y}}=\frac{\mathrm{V}_{\mathrm{Ey}}}{\sum \mathrm{k}_{\mathrm{i}}}
$$

where $\sum \mathrm{k}_{\mathrm{i}}$ is the translatory stiffness of the structural system with respect to the $y$ direction.

The definition of element stiffness by equation (7) suggest that, contrary to the traditional approach, strengths within a system need not necessarily be assigned in proportion to element stiffnesses. It has been found [14] that in the case of structural wall system, more advantage solutions can be achieved if element strength is assigned in proportion to the product of element area, $A_{g}$, and element length, $\ell_{w}$, rather than the second moment of area of the section of the element. As strength allocation is not directly relevant to the issues addressed in this paper, it is not discussed further.

The evaluation of the element stiffness, $k_{i}$, is required only when deflections of elastic elements, such as those affected by torsion during the ductile response of the system, need to be known. This is shown in Section 3.1.3.

\subsubsection{The centre of resistance}

Torsional effects during the ductile response of systems can be readily assessed, but only after the strength of all elements, $V_{i}$, as detailed, has been established. As a general rule the assignment of relative strength to elements, associated with the ultimate limit state, may be based on uniform diaphragm translations, as illustrated in figure 2 , with torsional effects ignored. With the knowledge of element strengths, $V_{i}$, the location of the total system resistance, $\sum V_{i}$, is known.

It may be readily obtained from

$$
\mathrm{e}_{\mathrm{vx}}=\frac{\sum \mathrm{x}_{\mathrm{i}} \mathrm{V}_{\mathrm{yi}}}{\sum \mathrm{V}_{\mathrm{yi}}}
$$

and

$$
\mathrm{e}_{\mathrm{vy}}=\frac{\sum \mathrm{y}_{\mathrm{i}} \mathrm{V}_{\mathrm{xi}}}{\sum \mathrm{V}_{\mathrm{xi}}}
$$

where $x_{i}$ and $y_{i}$ are the distances of elements measured from the centre of mass $\mathrm{CM}$ (figure 1 ) and $\mathrm{V}_{\mathrm{yi}}$ and $\mathrm{V}_{\mathrm{xi}}$ are element strengths developed during inelastic system displacement in the $y$ and $x$ directions, respectively. $e_{\mathrm{vx}}$ and $\mathrm{e}_{\mathrm{vy}}$ are strength eccentricities, these being distinctly different from the stiffness eccentricities traditionally used in code provisions. The latter are relevant only to elastic systems.

The point $\mathrm{CV}$ in figure 1 is thus referred to as the "centre of resistance" or "centre of strength". Its position is under the control of the designer. The assignment of strength to elements, such as (1) to (4) in figure 1, may be freely adjusted, if it is desired, to change the strength eccentricity, $\mathrm{e}_{\mathrm{vx}}$. If necessary, this eccentricity can be readily eliminated, so that $\mathrm{e}_{\mathrm{vx}}=0$.

It is evident that any torque that may arise at the ultimate limit state, such as

$$
\text { or } \quad \begin{aligned}
\mathrm{M}_{\mathrm{tx}} & =\mathrm{e}_{\mathrm{vx}} \Sigma \mathrm{V}_{\mathrm{yi}} \\
\mathrm{M}_{\mathrm{ty}} & =\mathrm{e}_{\mathrm{vy}} \Sigma \mathrm{V}_{\mathrm{xi}}
\end{aligned}
$$

must be resisted by elastic transverse elements, which have not been affected by the associated storey shear force. As a corollary, in the absence of elastic transverse elements, no eccentricity can exist at the ultimate limit state.

\subsubsection{Torsional restraint}

Torque- induced forces in elements, transverse to the direction of the base shear force, will result in elastic element deformations. These elements will then control the system twist, $\theta_{\mathrm{tu}}$. Figure 1 shows that under the action $\mathrm{V}_{\text {, }}$, the ensuing torque, $M_{t x}=e_{v x} V_{E y}$ will be resisted by the (T) type transverse elements. The deformations of these, generally well within the elastic domain of response, can be readily predicted. The $(\mathrm{T})$ type transverse element will thus provide torsional restraint by restricting the angle of twist, $\theta_{t u}$, at the ultimate limit state. The evaluation of and the parameters affecting torsional restraint was examined in greater detail elsewhere [11].

The angle of twist at the ultimate limit state is

$$
\begin{aligned}
\theta_{\mathrm{tu}} & =\frac{\mathrm{M}_{\mathrm{tx}}}{\mathrm{K}_{\mathrm{tx}}}=\frac{\mathrm{M}_{\mathrm{tx}}}{\sum \mathrm{y}_{\mathrm{ri}}^{2} \mathrm{k}_{\mathrm{xi}}} \\
\text { or } \quad \theta_{\mathrm{tu}} & =\frac{\mathrm{M}_{\mathrm{ty}}}{\mathrm{K}_{\mathrm{ty}}}=\frac{\mathrm{M}_{\mathrm{ty}}}{\sum \mathrm{x}_{\mathrm{ri}}^{2} \mathrm{k}_{\mathrm{yi}}}
\end{aligned}
$$

where $\mathrm{K}_{\mathrm{tx}}$ and $\mathrm{K}_{\mathrm{ty}}$ are residual torsional stiffnesses [14, 18] and $\mathrm{k}_{\mathrm{xi}}$ and $\mathrm{k}_{\mathrm{yi}}$ are element stiffnesses as defined by equation (7), and where $y_{r i}$ and $x_{r i}$ are distances from CR to element $i$ in the principal directions, respectively. 
Inelastic translatory elements cannot contribute to torsional resistance. However, a structure of the type shown in figure 1, when subjected independently in either of the orthogonal directions to base shear forces $V_{E y}$ or $V_{E x}$, is torsionally restrained by elastic transverse elements.

In contrast figure 3 shows a system which is torsionally unrestrained with respect to a base shear $V_{E y}$. Although a centre rigidity, $\mathrm{CR}$, exists, it is irrelevant to base shear resistance. For a given position of the centre of mass, $\mathrm{CM}$, the resisting element forces, $V_{1}$ and $V_{2}$, are determined only by equilibrium criteria. Hence $\mathrm{CM}$ and $\mathrm{CV}$ will coincide as at the ultimate limit state, no strength eccentricity can exist. The possibility of simultaneous yielding of these two elements at the commencement of ductile response of the real structures is remote and should not be expected. The ensuing twist, as the displacement patterns in figure 3 imply, is unrestrained. Torsional resistance during ductile response in the y direction, when the full strengths of both elements is mobilized, is absent. Eccentricity of the base shear, $\mathrm{V}_{\mathrm{Ey}}$, with respect to the centre of mass, CM, in figure 3 is only possible if the induced force in one of the elements is less than its strength. Thereby, as a result of such eccentricity, the total base shear capacity is reduced. Base shear-torque relationships [6], some examples of which were given in reference [11], enable such reduction of the base shear capacity to be readily quantified.

In contrast, in the orthogonal direction significant mass eccentricity with respect to the base shear, $V_{E x}$, to be resisted by element (3), can be sustained with any twist, $\theta_{\mathrm{tu}}$, which is well restrained by the elastic elements (1) and (2).
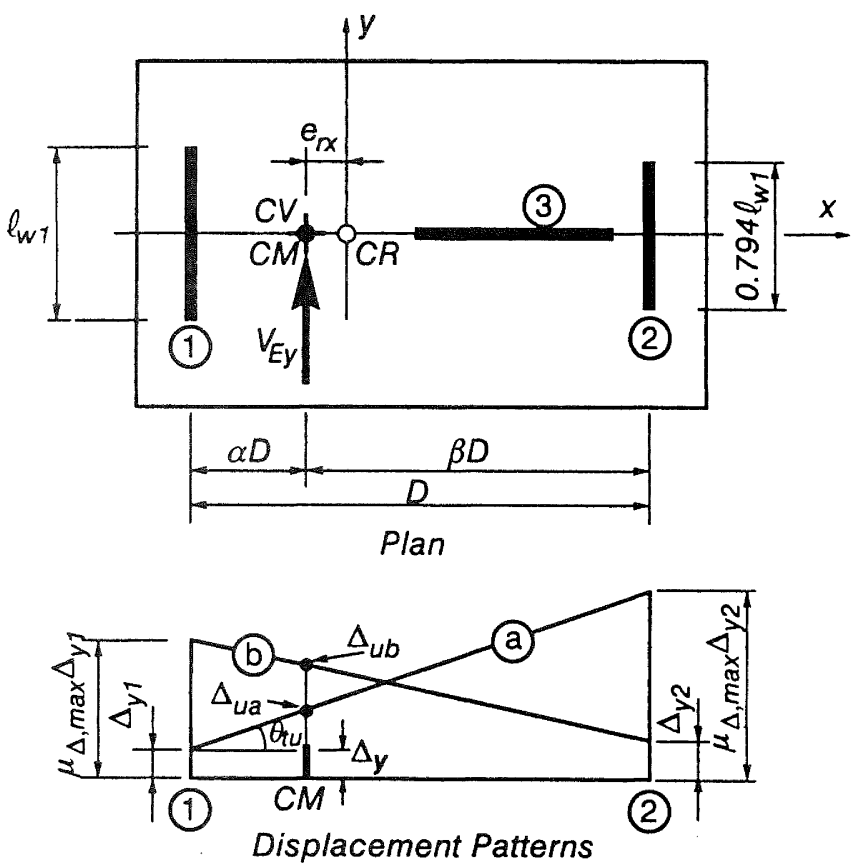

FIGURE 3. A torsionally unrestrained system subjected to ductility demands

\section{$3.2 \quad$ A Summary of Design Strategies}

Details of suggested design strategies, applicable to ductile buildings and based on both traditional and modified definitions of element stiffnesses, have been reported [11-13]. Only the major design steps are summarised here in support of proposed code modifications.

\subsubsection{Torsionally restrained systems}

The simple design steps involved are illustrated with respect to the specific example of figure 1. Unless the designer is interested in the absolute values of deformations, relative or normalized values of the design parameters, particularly in the preliminary stage of the design, may be used. These will greatly facilitate the speedy assessment of the likely ductile behaviour of the structure already at an early stage of the design process. Relative parameter values will be utilized in the subsequent description.

Assign lateral strength to elements (1) to (4), for example in terms of the total base shear, $V_{E y}$, so that an acceptably small strength eccentricity results. In this respect the designer has considerable freedom. Forces do not need to be assigned to lateral forceresisting wall elements in proportion to their flexural rigidity, EI. It has been shown, for example, [14] that strength allocation in proportion of $b_{w i} \ell_{w i}{ }^{2}$ results in approximately the same reinforcement ratio, $\mathrm{p}=\mathrm{A}_{\mathrm{st}} /\left(\mathrm{b}_{\mathrm{wi}} \ell_{\mathrm{wi}}\right)$ in all rectangular elements, where $b_{w i}$ is the width of the element $i$ and $A_{s t}$ is total vertical flexural reinforcement provided.

With the relative yield displacement of elements from equation (4)

$$
\Delta_{\mathrm{yi}} \propto 1 / \ell_{\text {wi }}
$$

the relative element stiffness can be determined from equation (7) thus

$$
\mathrm{k}_{\mathrm{i}} \propto \ell_{\text {wi }} \mathrm{V}_{\mathrm{i}}
$$

The subscripts y and $\mathrm{i}$ used above refer to yielding (rather than the direction $y$ ) and element identification, respectively.

(iii) The reference yield displacement of the system, to be used subsequently to quantify its displacement ductility capacity, is

$\Delta_{\mathrm{y}}=\frac{\mathrm{V}_{\mathrm{E}}}{\Sigma \mathrm{k}_{\mathrm{i}}}$

It needs to be determined for each of the principal directions of seismic attack, $x$ and $y$. The system reference yield displacement, $\Delta_{y}$, based on uniform diaphragm translation is shown in figure $1(\mathrm{~b})$ 
(iv) Once the strength elements, $\mathrm{V}_{\mathrm{i}}$, as detailed, has been determined, the position of the total resistance, for example with respect to the $y$ axis, shown in figure 1(a) as CV, is readily found. In figure 1 (a) it is implied that the strength of all $(\mathrm{T})$ type elements with respect to $V_{E x}$ is identical. Hence $e_{v y}=e_{r y}$.

With the knowledge of the strength eccentricity, $\mathrm{e}_{\mathrm{vx}}$ or $\mathrm{e}_{\mathrm{vy}}$, given by equations ( $\left.9 \mathrm{a}\right)$ and $(9 \mathrm{~b})$, the torque to be resisted at the ultimate limit state by elastic transverse elements, such as $\mathrm{M}_{\mathrm{tx}}=\mathrm{e}_{\mathrm{vx}} \sum \mathrm{V}_{\mathrm{yi}}$, are found. Hence the angle of twist, relevant to the ultimate limit state, $\theta_{\mathrm{tu}}$, is given by equations (11a) and $(11 \mathrm{~b})$. In a general form this is

$\theta_{\mathrm{tu}}=\frac{\mathrm{e}_{\mathrm{v}} \Sigma \mathrm{V}_{\mathrm{i}}}{\mathrm{K}_{\mathrm{t}}}$

where the torsional stiffness, $\mathrm{K}_{\mathrm{t}}$, is provided by the elastic transverse elements only.

The maximum acceptable ultimate displacement, imposed usually on one of the edge elements, $\Delta_{\mathrm{ui}}$, such as elements (1) or (4) in figure 1, must be limited to ensure that the displacement ductility capacity of that element, $\mu_{\Delta i \text { max }}$ is not likely to be exceeded. With the knowledge of the angle twist, $\theta_{\text {tu }}$, taken positive when associated with clockwise rotations, the maximum displacement at the centre of mass, CM, can then be simply found. In the case of the example structure shown in figure 1 , it is found that

$$
\begin{aligned}
\Delta_{\mathrm{u}} & =\Delta_{\mathrm{u} 1}-\mathrm{x}_{1} \theta_{\mathrm{tu}} \\
\text { or } \quad \Delta_{\mathrm{u}} & =\Delta_{\mathrm{u} 4}+\mathrm{x}_{4} \theta_{\mathrm{tu}}
\end{aligned}
$$

In these expressions the sign convention relevant to the co-ordinate system with its origin at $\mathrm{CM}$ (figure 1(a)) needs to be observed. (Note that $\theta_{\mathrm{tu}}<0$ ).

Hence the ductility demand on the system must be limited to the lesser of

$$
\begin{gathered}
\mu_{\Delta} \leq \frac{\Delta_{u}}{\Delta_{y}}=\frac{\mu_{\Delta 1, \max } \Delta_{y 1}-x_{1} \theta_{t u}}{\Delta_{y}} \\
\text { or } \mu_{\Delta} \leq \frac{\mu_{\Delta 4, \max } \Delta_{y 4}+x_{4} \theta_{t u}}{\Delta_{y}}
\end{gathered}
$$

Only rarely would intermediate elements, such as (2) and (3), in figure 1(a) need to be checked for displacement ductility demands. More extensive numerical examples of application are given elsewhere [14].

It is evident that the simple relationships, illustrated in figure 1 , can be readily used by the designer without having to rely on code-specified equations of the type of (13a) and (13b).

\subsubsection{Torsionally unrestrained systems}

With the aid of figure 3, it was explained in Section 3.1.5 that, in the absence of elastic transverse elements, the simultaneous yielding of all translatory elements cannot be expected. Hence, if the displacement ductility capacity of edge elements of such torsionally unrestrained systems is not to be exceeded, the system ductility demand, $\mu_{\Delta}$, must be drastically reduced. This may be easily established from the geometry of the element displacements, shown in figure 3. Alternatively, it may be shown that, depending on the position of the non-yielding element, the restrictions are as follows:

$\mu_{\Delta} \leq \beta \frac{\Delta_{y 1}}{\Delta_{y}}+\alpha \mu_{\Delta 2, \max } \frac{\Delta_{y 2}}{\Delta_{y}}$

$\mu_{\Delta} \leq \alpha \frac{\Delta_{y 2}}{\Delta_{y}}+\beta \mu_{\Delta 1, \max } \frac{\Delta_{y 1}}{\Delta_{y}}$

where the system yield displacement at $\mathrm{CM}$ is defined by equation (8).

The same procedure may be used when more than two elements are subjected to inelastic translations.

\subsubsection{Dynamic effects}

In establishing the displacement relationship between translatory elements, the effects on the angle of twist, $\theta_{t}$, of torsional inertia of the distributed mass has not been considered. This effect is not likely to be significant in torsionally restrained systems, where additional torsional resistance, associated with moderate changes in twist, can be readily mobilized. However, when torsional restraint is absent, the system may be more sensitive to dynamically induced twist. Preferably such systems should not be used.

\section{RECOMMENDATIONS FOR CODE PROVISIONS}

\subsection{General Requirements}

It would be desirable to present all requirements relevant to torsional effect in one main clause of Part 4 of NZS 4203:1992 [1]. Presently they are referred to under the requirements for structural regularity, accidental eccentricity and general analysis aspects of torsion.

It is recommended that torsional phenomena be treated for two distinct conditions; (a) elastic response associated with serviceability limit state criteria and (b) ductile response relevant to the ultimate limit state.

\subsection{Elastic Systems}

Because existing code [1] provisions, based either on static or modal spectral analyses, imply elastic response, they should be considered applicable only to serviceability limit state criteria or to systems which are required to be designed for elastic response also under ultimate limit state conditions $\left(\mu_{\Delta}<1.25\right)$. 
This approach implies a knowledge of the structural properties, such as element stiffnesses, and hence the shear centre*. Therefore it is an analysis rather than a design tool. In its present form it is thus suitable to evaluate the elastic response of a structural system that has already been designed.

The required magnitude of the magnification of stiffness eccentricities, with the use of an accidental eccentricity, to allow for uncertainties in locating both the centre of mass and the shear centre, dynamic and other effects, appears to be adequate [5]. The adverse combination of translational and torsional effects should be used for checking rather than design purposes.

Because predictions of elastic response are much more reliable than those relevant to ductile response, there appears to be no need to impose limits on stiffness eccentricities, such as $\mathrm{e}_{\mathrm{r}} \leq 0.3 \mathrm{~A}$, or on the angle of twist. ( $\mathrm{A}$ is the dimensions of building plan relevant to the earthquake attack considered.) The designer should be able to ascertain whether effects of torsional response, associated with a large eccentricity, or a low value of torsional stiffness, satisfy the deflection and strength criteria of the serviceability limit state. There appears to be no reason for disallowing a change of sign of the eccentricity over the height of the structure. This feature is inevitable in asymmetric dual systems [16].

\subsection{Ductile Systems}

It is recommended that new clauses, as part of a general section for torsional code provisions, should explicitly address the design of structures which, when meeting the requirements of the ultimate limit state, are expected to rely on ductility capacity. The recommendations presented here are in two groups, one suitable for possible adaption as code requirements, the other as a set of explanations serving as a commentary.

\subsubsection{Code proposals}

(a) The design criteria for the ductile seismic response of the buildings to be satisfied shall be:

Earthquake-induced deformations, including system twist, shall be such as to limit the expected displacement ductility demand on any element to its specified ductility capacity.

(ii) Magnitudes of interstorey displacements to be expected at locations remote from the centre of twist, shall not exceed those acceptable [1].

(b) In torsionally restrained systems, twist control shall rely on lateral force-resisting elastic elements transverse to the base shear under consideration.

\footnotetext{
"The "shear centre" or "centre of rigidity" is the point in plan in a storey where the applied lateral force results only in floor translation, i.e., without any twist of the unrestrained elastic system.
}

(c) The torque to be resisted shall be based on the strength eccentricity, i.e., the distance between the centre of mass and the centre of strength, identified by the location of the resultant of all the forces developed in elements, subjected to inelastic displacements, as designed and detailed, resisting the base shear.

From the yield displacements of the ductile translatory elements, the yield displacement of the system, at the centre of mass, shall be estimated. The acceptable ultimate system displacement at the centre of mass, taking into account its components due to storey translation and storey twist, shall be limited to ensure that the displacement ductility capacity of the critical element or elements, particularly those at the periphery of the building, will not be exceeded.

(e) In torsionally unrestrained systems, where transverse elements capable of resisting a torque within the elastic domain, are absent, the element and system ductility relationship shall be based on the assumption that one of the edge elements, while resisting a fraction of the storey shear force, will not yield.

In satisfying the above design criteria, the displacement ductility demand on the system will generally need to be reduced to values less than those assigned to ductile elements, such as frames or structural walls. The total design base shear shall be based on the reduced ductility capacity of the system.

\subsubsection{Proposals for commentaries}

(a) Because of storey twist, displacements, and hence ductility demands on elements of the structure, will be different. Ductility demands on elements should not exceed values specified by the material codes. The critically situated elements should satisfy the lateral and interstorey deflection criteria [1] for the ultimate limit state.

(b) In torsionally restrained systems, ductile elements, sustaining the storey shear, cannot be assumed to be able to resist any forces that may arise as a result of strength eccentricity. Torsional resistance must be assigned solely to transverse elements capable of resisting the corresponding shear forces within the elastic domain. Using the torsional stiffness provided only by these elastic transverse elements, the angle of storey twist is readily found.

(c) When the lateral force resistance of an element, subjected to inelastic displacements in one of the principal directions, is established using statics, the position of the resultant of all ductile elements is found. This is the centre of resistance with respect to the direction of the base shear considered. The distance between the centre of resistance and that of the mass is the strength eccentricity. This enables 
the torque due to the static base or storey shear force at the ultimate state to be defined.

Strength relevant to lateral force-resistance may be assigned to elements in any rational manner [14]. Design forces need to be proportional to traditionally defined element stiffnesses. Strength between parallel elements may be redistributed to optimize the strength eccentricity and hence storey twist. If desired, for example in system comprising ductile frames, the strength eccentricity may thus be eliminated.

(d)

To assess the ductility demands likely to be ultimately imposed on inelastic elements, their relative yield displacement, $\Delta_{\mathrm{yi}}$, needs to be estimated [14]. From these the yield displacement of the system, $\Delta_{\mathrm{y}}$, subjected to storey translation without twist, required to define the acceptable maximum ultimate system displacement, $\Delta_{u}$, can be estimated. The displacement ductility capacity of elements, $\mu_{\Delta i, \max }$, must be in accordance with the specification of the relevant material code. The steps involved in the evaluation of the system displacement ductility capacity, as affected by system twist, are summarized in Appendix A. Systems in which the elastic transverse elements provide small torsional stiffness, should be treated as torsionally unrestrained structures.

\begin{abstract}
The mechanism to be assumed for torsionally unrestrained structural systems is also shown in Appendix A together with the simple geometry of displacement patterns which enable a system displacement ductility capacity to be readily estimated. Because of the lack of twist control and the likely sensitivity of such systems to dynamic torsional effects, their use should be avoided.
\end{abstract}

\section{CONCLUSIONS}

Proposals were made for a revision of the existing torsional provisions of the General Structural Design and Design Loadings Code for Buildings of New Zealand [1]. It is recommended the different requirements be formulated to satisfy serviceability and ultimate limit state criteria, respectively. The former should be controlled by the principles of elastic structural response, while the latter should address features affecting displacement ductilities of elements and the inelastic structural system. To aid an appreciation of the concepts on which these proposals were based, elementary aspects of structural behaviour, both elastic and ductile, were reviewed. To illustrate the ease with which the proposed code requirements could be implemented, specific examples are also presented.

\section{ACKNOWLEDGEMENTS}

This work benefitted greatly from the concepts of capacity design, developed over the last two decades in New Zealand, and the inspiration received from Professor Nigel Priestley, particularly his postulates with respect to myths and fallacies in earthquake engineering [18]. The contribution of Mr Desmond Bull to improvements and clarity in presentation is gratefully acknowledged.

\section{REFERENCES}

1 Standard Association of New Zealand, (1992). Code of Practice for General Structural Design Loadings for Buildings, NZS 4203:1992, Wellington.

2 International Association for Earthquake Engineering, (1996), Regulations for Seismic Design - A World List. (IAEE Tokyo). pp 1197

Rutenberg, A. (1992), Nonlinear response of asymmetric building structures and seismic codes: A state of the art review0, Nonlinear Seismic Analysis and Design of Reinforced Concrete Buildings, eds. Fajfar, P. \& Krawinkler, H. (Elsevier Applied Science, London) pp. 281-305.

Rutenberg, A, Chandler, A M, Duan, X N and Corrrenza, J C (1995). Nonlinear seismic response of asymmetric structures: Bibliography, National Building Research Institute, Israel, pp 21.

Tso, W K and Wong, C M (1993). An evaluation of the New Zealand code torsional provision, Bulletin of the New Zealand National Society for Earthquake Engineering. 26 (2): 194-207.

$6 \quad$ De La Llera, J and Chopra, A (1995). Understanding of inelastic seismic behaviour of asymmetric-plan buildings, Earthquake Engineering and Structural Dynamics, 24, 549 - 572.

Goel, K Rakesh and Chopra, Anil K, (1990). Inelastic Seismic Response of one-storey, asymmetric plan systems: Effects of stiffness and strength distribution, Earthquake Engineering and Structural Dynamics, 19, 949-970.

Chopra, K Anil and Goel, Rakesh K, (1991). Evaluation of torsional provisions in seismic codes, Journal of Structural Engineering, ASCE, 117(12) 3762-3782.

9 Bertero, Ral D, (1995). Inelastic Torsion for Preliminary Seismic Design. Journal of Structural Engineering, ASCE, 121(8):1183-1189.

10 Chandler, Adrian M, X N Duan and Rutenberg, A (1996). Seismic torsional response: assumptions, controversies and research progress, European Earthquake Engineering (1) 37-51.

Paulay, T, (1996). Seismic design for torsional response of ductile buildings, Bulletin of the New Zealand National Society for Earthquake Engineering, 29 (3), 178-198. 
12 Paulay, T, (1997). Are existing seismic torsional provisions achieving the design aims? Earthquake Spectra, in press.

13 Paulay, T, (1997). Displacement-based design approach to earthquake-induced torsion in ductile buildings, Engineering Structures, in press.

14 Paulay, T, (1997). Seismic torsional effects on ductile structural wall systems, Journal of Earthquake Engineering, in press.

15 Park, R and Paulay, T, (1975). Reinforced Concrete Structures, John Wiley and Sons, New York, pp 769.

16 Paulay, T and Priestley, M J N, (1992). Seismic Design of Reinforced Concrete and Masonry Structures, (John Wiley and Sons, New York), pp 767.

17 Standards New Zealand NZS 3101:1995. Concrete Structures Standard Part 1 - The design of concrete structures, Part 2-Commentary on the design of concrete structures.

18. Priestley, M J N, (1993). Myths and Fallacies in Earthquake Engineering - Conflicts between Design and Reality, ACI SP-157, Recent Developments in Lateral Force Transfer in Buildings, 231-246.

\section{APPENDIX A - TORSIONAL EFFECTS IN DUCTILE BUILDINGS DUE TO EARTHQUAKE ACTIONS}

\section{A1 General}

If it is decided that fundamental changes should be introduced then with appropriate editing an appendix, such as this, could be added to the code. This appears to be necessary because the approach, although simple, is new and hence generally unfamiliar to design practitioners. The illustrations suggested for incorporation into such an appendix, such as figures 1 and 3 , are not reproduced here.

\section{A2 Design Steps for Structural Wall Systems}

Step 1. Using established or other analysis procedures, assign strength, $V_{i}$, to the wall elements. A well balanced design is likely to result if element strengths are assigned approximately in proportion of $\mathrm{A}_{\mathrm{gi}} \ell_{\text {wi }}$, where $\mathrm{A}_{\mathrm{gi}}$ is the gross area and $\ell_{\text {wi }}$ is length of the section of element $i$. Torsion at this stage may, but need not, be considered. However, a relatively small strength eccentricity should be aimed at. The elimination of strength eccentricity is advantageous only if all elements have the same length.

Step 2. When considering the ductile response in the $y$ direction of the structure shown in figure 1(a), determine the strength eccentricity with respect to the centre of mass thus

$$
\mathrm{e}_{\mathrm{vx}}=\frac{\sum \mathrm{x}_{\mathrm{i}} \mathrm{V}_{\mathrm{i}}}{\sum \mathrm{V}_{\mathrm{i}}}
$$

where $x_{i}$ is the distance of the element measured from the centre of mass.

If this eccentricity appears to be large, redistribute strength between elements to reduce $\mathrm{e}_{\mathrm{vx}}$.

Step 3. Estimate the relative yield displacements of elements

$$
\Delta_{\mathrm{yi}} \propto 1 / \ell_{\mathrm{wi}}
$$

Step 4. The relative stiffness of wall element is then

$$
\mathrm{k}_{\mathrm{i}}=\mathrm{V}_{\mathrm{i}} / \Delta_{\mathrm{yi}}
$$

Step 5. Estimate the relative yield displacement of the entire system in given direction of the relevant base shear with

$$
\Delta_{\mathrm{y}} \propto \frac{\Sigma \mathrm{V}_{\mathrm{i}}}{\sum \mathrm{k}_{\mathrm{i}}}
$$

Step 6. For the base shear in the y direction (figure 1a) determine, with allowance for its sign, the relative angle of twist from

$$
\theta_{\mathrm{tu}}=\frac{\mathrm{e}_{\mathrm{vx}} \Sigma \mathrm{V}_{\mathrm{i}}}{\mathrm{K}_{\mathrm{tx}}}
$$

where $\mathrm{K}_{\mathrm{tx}}=\Sigma\left(\mathrm{y}_{\mathrm{ri}}^{2} \mathrm{k}_{\mathrm{xi}}\right)$

is the torsional stiffness of the elastic transverse $(\mathrm{T})$ type elements shown in figure 1 . The relative stiffness $\left(\mathrm{k}_{\mathrm{xi}}\right)$ of these elements is given by equation (A3) and $\mathrm{y}_{\mathrm{ri}}$ is the distance of the elastic transverse element from the level of the centre of rigidity. For this level the familiar condition, $\Sigma\left(y_{r i} k_{x i}\right)=0$, needs to be satisfied.

Step 7. The displacement ductility capacity of the system, $\mu_{\Delta}$, with respect to the base shear, $V_{E y}$, is then the lesser of:

$$
\mu_{\Delta}=\frac{\mu_{\Delta 1, \max } \Delta_{\mathrm{y} 1}-\mathrm{x}_{1} \theta_{\mathrm{tu}}}{\Delta_{\mathrm{y}}}
$$$$
\text { or } \quad \mu_{\Delta}=\frac{\mu_{\Delta 4, \max } \Delta_{y 4}+x_{4} \theta_{t u}}{\Delta_{y}}
$$

where $\mathrm{x}_{1}$ and $\mathrm{x}_{4}$ give the locations of the respective elements measured from CM.

Step 8. Determine the base shear intensity corresponding with the fundamental period of vibration of the building and the system ductility capacity, $\mu_{\Delta}$, found in Step 7 . 
A3

\section{Design Steps for Frame Systems}

With significant simplifications the procedure described in section A2 applies. As the depth of members, such as those shown in figure 4(a) are not likely to differ significantly, it should be sufficient to assume that element yield displacements, $\Delta_{\mathrm{yi}}$, are very similar and equal to the system yield displacement, $\Delta_{\mathrm{y}}$. With this simplification the procedure concludes with the determination of the system displacement ductility, $\mu_{\Delta}$, controlled, as figure 4(b) shows, by the maximum acceptable displacement imposed on frame element (4) thus

$$
\mu_{\Delta} \leq \mu_{\Delta, \text { max }}+\frac{\mathrm{x}_{4}}{\Delta_{\mathrm{y}}} \theta_{\mathrm{tu}}
$$

where $\mu_{\Delta \max }$ is the displacement ductility capacity of all frames and $\theta_{\mathrm{tu}}<0$. This is a corresponding modification of equation (A7b).

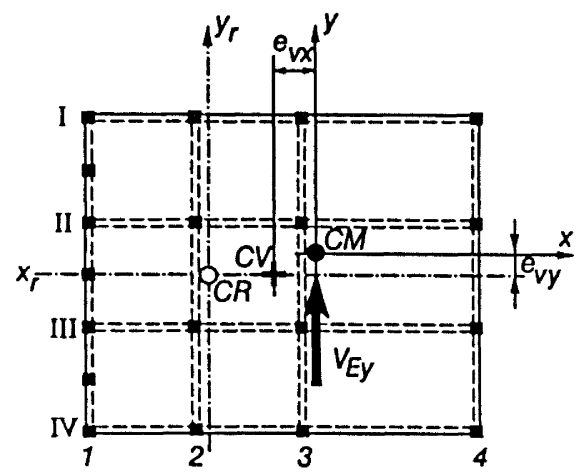

(a) Plan

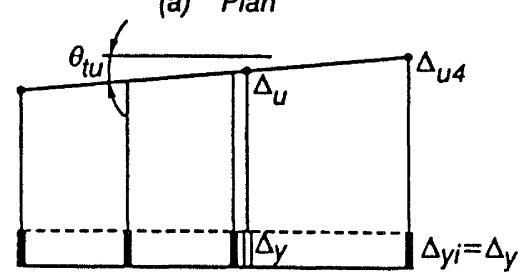

(b) Displacement pattern

FIGURE 4

\section{A torsionally restrained system comprising ductile frames}

\section{APPENDIX B - EXAMPLES}

B1

\section{Example 1: A Torsionally Restrained Structural Wall System}

Determine the acceptable system displacement ductility demand, $\mu_{\Delta}$, on the modal structure shown in plan in figure 5(a). Assume that the ductility capacity for all elements is $\mu_{\max }=5.0$. All relevant dimensions are given in terms of the width, B, of the floor plan. The element layout suggests that large eccentricities with respect to the $y$ axis may exist. Consider therefore also a possible revision of the design, whereby the adverse torsional effects could be alleviated without changing the element layout. Where necessary reference is made to the relevant design step listed in Section A2.

\section{B1.1 Dimensions}

The length of the rectangular wall elements with identical width, expressed in terms of the length of element (1), $\ell_{\mathrm{wl}}$, are as follows:

$$
\begin{array}{ll}
\ell_{\mathrm{w} 2}=0.667 \ell_{\mathrm{w} 1} & \ell_{\mathrm{w} 4}=0.667 \ell_{\mathrm{w} 1} \\
\ell_{\mathrm{w} 3}=0.833 \ell_{\mathrm{w} 1} & \ell_{\mathrm{w} 5}=0.833 \ell_{\mathrm{w} 1} \\
\ell_{\mathrm{w} 6}=1.000 \ell_{\mathrm{w} 1}
\end{array}
$$

\section{B1.2 Allocation of element strength}

In accord with the suggestion made in Step 1, without considering any torsional effects, element strengths, to resist a base shear $\mathrm{V}_{\mathrm{Ey}}=1.000$, will be assigned in proportion to the square of element lengths, $\ell_{\text {wi }}$. Therefore:

$\mathrm{V}_{1}=0.468, \quad \mathrm{~V}_{2}=0.208$ and $\mathrm{V}_{3}=0.324$

The strength eccentricity is now found from equation (A1) in Step 2, to be $\mathrm{e}_{\mathrm{vx}}^{\prime}=-0.428 \mathrm{~B}$. As seen in the figure 5(a) this is an obviously large distance.

\section{B1.3 Relative yield displacements and stiffnesses}

From equations (A2) and (A3) given in Steps 3 and 4, it is found that:

$$
\begin{array}{ll}
\Delta_{y 1}=\Delta_{y 6}=1 / 1.000=1.0 & \text { and } \quad k_{1}=k_{6}=0.468 / 1.0=0.468 \\
\Delta_{y 2}=\Delta_{y 4}=1 / 0.667=1.5 & \text { and } \quad k_{2}=k_{4}=0.208 / 1.5=0.139 \\
\Delta_{y 3}=\Delta_{y 5}=1 / 0.833=1.2 & \text { and } \quad k_{3}=k_{5}=0.324 / 1.2=0.270
\end{array}
$$

Hence from equation (A4) in Step 5, with $\sum k_{i}=0.877$, the system yield displacement is

$\Delta_{\mathrm{y}}=1.000 / 0.877=1.14$

\section{B1.4 Torsional effects}

The centre of rigidity, $\mathrm{CR}$, of the system, based on element stiffnesses derived in B1.3, is as shown in figure 5 (a). The torsional stiffness provided only by the elastic elements, (4), (5) and (6) is from equation (A6), $\mathrm{K}_{\mathrm{tx}}=0.218 \mathrm{~B}^{2}$. The torque to be resisted at the ultimate limit state is $\mathrm{M}_{\mathrm{t}}=-0.428 \mathrm{~B} \sum \mathrm{V}_{\mathrm{i}}$. Hence from equation (A5) given in Step 6, the relative angle of twist is:

$$
\theta_{\mathrm{tu}}^{\prime}=-\frac{0.428 \mathrm{~B} \Sigma \mathrm{V}_{\mathrm{i}}}{0.218 \mathrm{~B}^{2}}=-1.963 / \mathrm{B}
$$

It may be shown that the torsion-induced forces, although in this case rather large, are less than the strength likely to be assigned to the transverse elements required to resist a unit base shear in the $\mathrm{x}$ direction. 


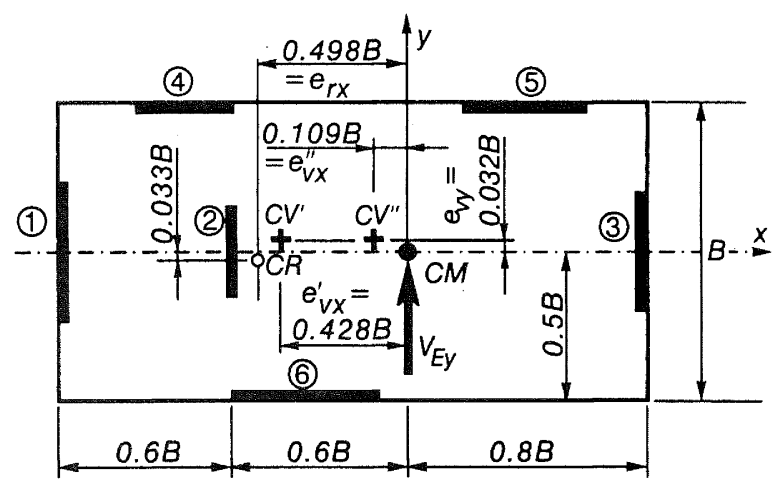

(a) Plan

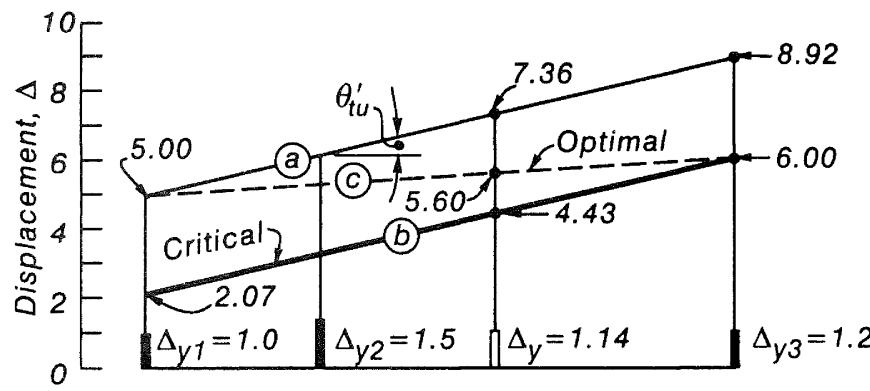

(b) Displacement patterns

\section{FIGURE 5. A torsionally restrained example structure}

\section{B1.5 The system displacement ductility capacity}

Two possible displacement patterns associated with a storey twist of $\theta_{t u}=-1.963 / \mathrm{B}$ are shown by lines (a) and (b) in figure 5(b). From these or using equations (A7a) and (A7b) given in Step 7, we find that when $\mu_{\Delta, \max }=5.0$

$$
\mu_{\Delta \mathrm{a}}=(5 \times 1.0-1.2 \mathrm{~B}(-1.963 / \mathrm{B})) / 1.14=6.45>5.0
$$

Note that $\mu_{\Delta}=6.45$ would result in a ductility demand on element 3 of

$$
\mu_{\Delta 3}=(5+2 \times 1.963) / 1.2=7.44>5.0
$$

When element 3 controls the response

$$
\mu_{\Delta b}=(5 \times 1.2+0.8 \mathrm{~B}(-1.963 / \mathrm{B})) / 1.14=3.89 \text { governs! }
$$

In this case the ductility demand on element (1) is only

$$
\mu_{\Delta}=(5 \times 1.2-2 \times 1.963) / 1.00=2.07 \text {. }
$$

\section{B1.6 A review of the structural layout}

It is evident that, because the uneven distribution of inelastic displacements among elements, the ductile performance of the structure is inefficient. In a force-based [1] design approach the base shear intensity would need to be increased by nearly $30 \%$ if the system ductility demand was to be limited to 3.89 .

Because of the small eccentricities associated with the base shear in the $\mathrm{x}$ direction and the considerably larger torsional restraint provided by the elastic elements (1), (2) and (3), the influence of torsion on ductile response will be negligible. Hence corresponding details are not given here.

\section{B1.7 A revision of the design}

An adjustment of element geometry and positions could result in a drastic reduction of the strength eccentricity, $e_{\mathrm{vx}}^{\prime}$. It will be assumed, however, that functional requirements do not allow element lengths and positions shown in figure 5 (a) to be altered. In this case, as was pointed out, the designer is free to redistribute strengths among elements (1), (2) and (3) so as to reduce the strength eccentricity considerably.

The displacement pattern (c) shown in figure 5(b) demonstrates that for the given dimensions of these elements, which determine element yield displacements, $\Delta_{\mathrm{yi}}$, an optimal solution can be readily found. The simultaneous development of the maximum ductility capacity of $\mu_{\max }=5.0$ at elements (1) and (3) would result in a relative ultimate displacement of $\mathrm{CM}$ of $\Delta_{u}=5.60$. Hence the system displacement ductility demand could be increased from 3.89 to $\mu_{\Delta}=5.60 / 1.14=4.91$.

The displacement profile (c) in figure 5(b) is possible if the angle of twist is reduced to $(5-6) / 2 \mathrm{~B}=-0.5 \mathrm{~B}$. This can be readily achieved if, for example, the redistribution of design forces from element (1) to (3) would result in a reduction of the strength eccentricity at the ultimate limit state to

$$
\mathrm{e}_{\mathrm{vx}}=\frac{0.5}{1.963} 0.428 \mathrm{~B}=0.109 \mathrm{~B}
$$

This would involve a redistribution of a design force of

$$
\Delta \mathrm{V}^{\prime \prime}=\frac{(0.428-0.109) \mathrm{B} \sum \mathrm{V}_{\mathrm{i}}}{2 \mathrm{~B}}=0.16 \sum \mathrm{V}_{\mathrm{i}}
$$

from element (1) to element (3). The modified strength of these two elements would thus need to be

$$
\begin{aligned}
& \mathrm{V}_{1, "}=(0.468-0.16) \sum \mathrm{V}_{\mathrm{i}}=0.308 \\
& \mathrm{~V}_{3}=(0.324-0.16) \sum \mathrm{V}_{\mathrm{i}}=0.484 \\
& \text { with } \mathrm{V}_{2}=\text { unchanged at }=0.208
\end{aligned}
$$

This would imply approximately $34 \%$ decrease and $50 \%$ increase of the reinforcement in elements (1) and (3) respectively, a feature readily achieved.

- Should an accidental eccentricity at the ultimate limit state, for example of the order of $\mathrm{e}_{\mathrm{va}}= \pm 0.05$ (2B) $=$ $\pm 0.1 \mathrm{~B}$, considered to be prudent, it may be readily shown that for

$$
\begin{aligned}
& \mathrm{e}_{\max }=-0.209 \mathrm{~B}, \mu_{\Delta}=4.6 \\
& \text { and } \quad \mathrm{e}_{\min }=-0.009 \mathrm{~B}, \mu_{\Delta}=4.4
\end{aligned}
$$

This latter value demonstrates that increased strength eccentricity does not necessarily aggravate the reduction of system ductility capacity. 
B2

\section{EXAMPLE 2: A Torsionally Unrestrained} System

Determine the system displacement ductility capacity of the torsionally unrestrained model structure shown in figure 3 . Assume that $\alpha=0.25$ and $\beta=0.75$ and the displacement ductility capacity of the elements is $\mu_{\Delta, \max }=5.0$. From the wall dimensions given, the element yield displacements are:

$$
\Delta_{\mathrm{y} 1}=1 / 1=1.0 \text { and } \Delta_{\mathrm{y} 2}=1 / 0.794=1.26 \text {. }
$$

The assignment of element strength for a base shear of $\mathrm{V}_{\mathrm{Ey}}=1.0$ follows from the requirements of statics thus:

$$
\mathrm{V}_{1}=0.75 \text { and } \mathrm{V}_{2}=0.25 \text {. }
$$

Hence the element stiffnesses are $\mathrm{k}_{1}=0.75 / 1.0=0.75$ and $\mathrm{k}_{2}=$ $0.25 / 1.26=0.198$. Therefore $\sum k_{i}=0.948$ and the system yield displacement is $\Delta_{\mathrm{y}}=1 / 0.948=1.05$.

From the geometry of the possible displacement patterns shown in figure 3(b), or from equations (14a) and (14b), it is seen that when element ( 1 ) cannot yield

$$
\mu_{\Delta \mathrm{a}}=0.75 \frac{1.00}{1.05}+0.25 \times 5 \times \frac{1.26}{1.05}=2.21 \text { governs! }
$$

and when element (2) cannot yield

$$
\mu_{\Delta b}=0.25 \frac{1.26}{1.05}+0.75 \times 5 \times \frac{1.00}{1.05}=3.87>2.21
$$

An eccentricity of the unit base shear, such as $\mathrm{e}_{\mathrm{dx}}=0.1 \mathrm{D}$, as a result of possible mass rotation, would not make such a difference to the system displacement ductility demand. However, the ensuing torque would reduce the base shear capacity of the structure by $\left(2 \mathrm{e}_{\mathrm{dx}} / \mathrm{D}\right) \mathrm{V}_{\mathrm{Ey}}$, i.e., $20 \%$. 